\title{
SELECTION OF HIGH YIELDING LINES FROM HETEROGENEOUS JORDANIAN BARLEY LANDRACES UNDER WELL WATERED AND DROUGHT STRESS CONDITIONS
}

(Received: 28.11.2012)

\author{
By \\ A. H. Abdel-Ghani \\ Department of Plant Production, Faculty of Agriculture, Mutah University, Karak, Jordan
}

\begin{abstract}
Nine agronomic traits were recorded on one hundred and sixty five barley lines under well watered and drought stress conditions. The objectives were to estimate the heritability and expected genetic advance from selection for yield, yield components, plant height and phenological traits and to examine the interrelationships among these traits. Results showed a significant $(\mathrm{P}<0.01)$ reduction in yield and growth under drought compared to well-watered conditions. Higher estimates of heritability and phenotypic/genotypic variances were observed under well watered than under drought conditions, which might indicate that direct selection under well watered conditions is more efficient to improve yield and/or plant biomass than indirect selection under drought. Higher heritability values were found to be associated with high predicted genetic advance from selection for grain yield, biological yield and yield components in well watered environment, indicating that heritability of these characters is most likely due to additive gene effects. Positive associations were found between grain yield and yield components combined with high magnitude of heritability and genetic advance, indicating that direct selection for yield per se or indirect selection for yield components would be effective to improve plant biomass. First three principle components explained more than $60 \%$ of total genetic variation with high loading from grain yield and yield components, indicating that these traits account for a maximal amount of total variance present among studied barley lines. In conclusion, our results showed that heterogeneous barley populations are a valuable source to expand genetic variability in barley and to select high performing lines.
\end{abstract}

Key words: barley, drought, landraces, selection.

\section{INTRODUCTION}

Barley is one of the important staple cereals in the arid and semi-arid regions of the world (Ceccarelli 1987 and Abdel-Ghani et al., 2005). It is well adapted to a variety of environmental conditions, with high variability in the amount and distribution of the rainfall (Ceccarelli and Grando, 1996). Modern barley varieties respond well to high input conditions and other improved managements, however, they are generally susceptible to both biotic and abiotic stresses as compared to landraces (van Lammerts Bueren et al., 2003 and Agorastos and Goulas, 2005). Consequently; the rate of adoption of new varieties by farmers is low. On the other side, landraces perform well under sub-optimal conditions as they are well adapted to local stresses and possess farmers' preferable traits (Ceccarelli et al., 1987). Landraces from Fertile Crescent were extensively studied; they showed a high degree of variability in morphological and developmental traits, disease resistance, protein content, allozymes and at DNA level (Jaradat, 1991, Jaradat, 1992; Nevo et al., 1984; Weltzien, 1988; Weltzien and Fischbeck, 1990 and Istaitie, 2005). In general, they are specific in adaptation and relatively stable in yield under low input agriculture and variable environmental conditions (Tesfaye et al., 1991).

Barley is a self-pollinating crop, and as a result of extensive inbreeding, barley became extremely narrow in its genetic base (Hawkes, 1977). This lack of genetic diversity leaves the barley crop vulnerable to widespread disease epidemics and abiotic stresses such as drought and salt stress. The rate of advancement of crop improvement mainly depends upon the amount of existing natural genetic variability for various crop economic characters. Barley landraces may be considered as a rich source of variability, which could be further utilized for barley improvement. Unlike crops of inbred species that are cultivated 
as pure lines in developed countries, barley is maintained as a genotypic mixture through its centers of domestication in Fertile Crescent. Therefore, it must not be forgotten too that there are differences in yield when landraces are evaluated as populations and when individual lines extracted from them are evaluated (Ceccarelli and Grando, 2000). High yielding lines could be isolated from heterogeneous barley populations and used either to develop mixtures of high yielding lines or lines with desirable traits that could be used as parents in hybridization to incorporate additional desirable traits (Ceccarelli and Grando, 2000).

Sufficient genetic variability is essential to enhance the yield potential of barley. Heritability estimate is an important population parameter for barley breeding because it provides an idea of the extent of genetic control for the expression of a particular character (Ceccarelli, 1989 and AbdelGhani et al., 2005). Moreover, heritability serves as a reliable estimate of the magnitude of genetic variability among genotypes constituting a population and hence determines success of selection procedure (Falconer and Mackay, 1996). According to Johnson et al. (1955), heritability estimates together with genetic advance are more important than heritability alone to predict the amount of the genetic improvement that could be achieved by selecting the highest performing genotypes.

Drought is perennial and serious problem, particularly in West Asia and North Africa (WANA). Also, climate change now seriously affects agricultural production including cereal all over the world (Forster, 2004). In WANA, landraces are common in droughted areas where inputs are low and where there is a high risk of crop failure. The strategy of barley breeding for stressed environments is proposed by the International Center for Agricultural Research in the Dry Areas (ICARDA). Their strategy was based on selecting high yielding lines in target environments, and developing heterogeneous seed (mixtures and landraces) from high yielding lines (Ceccarelli and Grando, 2000). In a country like Jordan, where landraces are still prevailing, the first step in breeding is to maximize the utilization of indigenous barley materials. A modification of phenotypic mass selection by selecting pure lines from heterogeneous barley populations has been suggested to improve the productivity of the landrace cultivars grown by the farmers (Tesfaye et al., 1991). Information on the heritability of agronomic traits and phenotypic correlations among these traits will be useful for planning suitable breeding strategies for improving yield under near optimum and drought stress conditions. Phenotypic relationships among traits are also important when simultaneous selection of multiple traits is to be carried out for high yield. Therefore, the present research was undertaken to estimate heritability of agronomic traits under well watered and drought stress and to examine the interrelationship among these traits. Moreover, this study was attempted to show the possibility for the improvement of indigenous barley landraces from Jordan by identifying high yielding pure lines which could be used directly by farmers and by isolating pure lines with better 'agronomic base' for use as potential parents in the further improvement of barley germplasm.

\section{MATERIALS AND METHODS \\ 2.1. Plant materials}

Single spike progenies (i.e. pure lines) used in this study were derived from barley landrace materials that were collected in 2004/2005 growing season from different ecogeographical regions of Jordan (Table 1). Genetic material used in this study consisted of 11 populations of 15 lines each (165 lines in total). The collection sites represent a wide range of annual rainfall ranging from 152 to $547 \mathrm{~mm}$ and covered low-high altitudes ranging from 490 to $1460 \mathrm{~m}$. Average annual temperature ranged among collection sites from 12.4 to $19.0^{\circ} \mathrm{C}$ with wide ranges of variation among months. The geographical position of each field (as latitude, longitude and altitude) was determined using the Global Positioning System (GPS). Long-term average seasonal rainfall and monthly temperature data were obtained from the Water Authority of Jordan and the Jordan Meteorological Department. In addition, two six row check varieties were included in the experiments for comparison.

\subsection{Experimental conditions and design}

This experiment was conducted in two seasons $(2005 / 2006$ and 2006/2007) in an open greenhouse from December $1^{\text {st }}$ until the middle of May. Plastic pots, $20 \mathrm{~cm}$ in diameter and $40 \mathrm{~cm}$ deep were filled with $8 \mathrm{~kg}$ soil taken from a field which was left fallow for many years. Collected soil was air-dried and sieved through a $2 \mathrm{~mm}$ mesh. The soil used in the pot experiment contained $56 \%$ sand, $15 \%$ silt, $29 \%$ clay, alkaline $\mathrm{pH}$ of (7.8), $1.3 \%$ organic matter, 640 p.p.m. total nitrogen $(\mathrm{N}), 18 \mathrm{ppm}$. available (olsen) phosphorus (P), $22 \%$ calcium carbonate, cation exchange capacity of 52.7 milli-equivalent 
Table (1): Ecogeographical information about barley collection sites in Jordan.

\begin{tabular}{|c|c|c|c|c|c|c|c|c|c|c|c|c|c|c|c|c|}
\hline Region & Site & Village & Latitude & Longitude & $\begin{array}{l}\text { Annual } \\
\text { rainfall }\end{array}$ & $\begin{array}{r}\text { Altitude } \\
(\mathbf{m})\end{array}$ & \multicolumn{9}{|c|}{ Temperature during the growing season } & \multirow{2}{*}{$\begin{array}{c}\text { Yearly } \\
\text { Temp. }\end{array}$} \\
\hline \multirow[t]{5}{*}{ Northern } & & & & & & & $\mathbf{O}$ & $\mathbf{N}$ & D & $\mathbf{J}$ & $\mathbf{F}$ & $\mathbf{M}$ & $\mathbf{A}$ & $\mathbf{M}$ & $\mathbf{J}$ & \\
\hline & Irbid & SaL & ${ }^{\circ} 32 ' 39$ & ${ }^{\circ} 35^{\prime} 49$ & 478 & 490 & 20.8 & 5.5 & 10.6 & 9.0 & 9.9 & 12.2 & 16.6 & 20.3 & 23.7 & 17.7 \\
\hline & Ajloun & Samta & ${ }^{\circ} 32 ' 24$ & ${ }^{\circ} 35^{\prime} 49$ & 547 & 1034 & $\mathbf{1 7 . 5}$ & 11.9 & 7.1 & 5.5 & 6.6 & 8.8 & 12.8 & $\mathbf{1 7 . 1}$ & 19.7 & 14.2 \\
\hline & Jarash & Om Qntara & ${ }^{\circ} 32 ' 17$ & ${ }^{\circ} 35^{\prime} 56$ & 350 & 610 & 20.9 & 15.3 & 10.5 & 8.9 & 10 & 12.2 & 16.2 & 20.5 & 23.1 & 17.6 \\
\hline & Mafaraq & Manshia & ${ }^{\circ} 32 ' 24$ & ${ }^{\circ} 36^{\prime} 05$ & 152 & 850 & 19.1 & $\mathbf{1 3 . 5}$ & 8.8 & 7.3 & 8.9 & 11.5 & 15.7 & 19.6 & 22.7 & 16.5 \\
\hline \multirow[t]{4}{*}{ Central } & Amman & Sahab & ${ }^{\circ} 31 ' 52$ & ${ }^{\circ} 35^{\prime} 58$ & 275 & 878 & 20.3 & 14.8 & 9.8 & 8.0 & 9.1 & 11.7 & 15.9 & 20.5 & 23.6 & $\mathbf{1 7 . 3}$ \\
\hline & Salt & Yazidia & ${ }^{\circ} 32 ' 05$ & ${ }^{\circ} 35^{\prime} 46$ & 200 & 885 & 16.2 & 11.0 & 6.8 & 4.5 & 4.3 & 6.3 & 10.5 & 15.4 & 14.8 & 19.0 \\
\hline & Ma'daba & Team & ${ }^{\circ} 31 ' 44$ & ${ }^{\circ} 35^{\prime} 45$ & 358 & 785 & 19.3 & 14.1 & 8.9 & 8.3 & 9.5 & 11.5 & 15.3 & 19.2 & 22.2 & 16.6 \\
\hline & Dieban & Baraza & ${ }^{\circ} 31 ' 34$ & ${ }^{\circ} 35^{\prime} 43$ & 270 & 715 & 18.7 & $\mathbf{1 3 . 5}$ & 8.3 & 7.7 & 8.9 & 10.9 & 14.7 & 18.6 & 21.6 & 16.0 \\
\hline \multirow[t]{5}{*}{ Southern } & Karak & Faqo & ${ }^{\circ} 31 ' 16$ & ${ }^{\circ} 35^{\prime} 45$ & 326 & 890 & 19.1 & 14.2 & 9.4 & 7.9 & 8.8 & 11.2 & 15.0 & 18.8 & 21.8 & 16.2 \\
\hline & & Mu'tah & ${ }^{\circ} 31^{\prime} 03$ & ${ }^{\circ} 35^{\prime} 24$ & 305 & 1200 & 17.1 & 12.2 & 6.4 & 5.9 & 6.8 & 9.2 & 13.0 & 16.8 & 19.8 & 14.2 \\
\hline & Tafila & Al Bada & ${ }^{\circ} 30 ' 47$ & ${ }^{\circ} 35^{\prime} 35$ & 250 & 1200 & 18.2 & 12.5 & 8.1 & 6.6 & 7.9 & 10.2 & 14.5 & 18.1 & 21.3 & 15.5 \\
\hline & Shoubak & Ghair & ${ }^{\circ} 30$ '32 & ${ }^{\circ} 35$ '35 & 315 & 1460 & 14.5 & 9.5 & 5.4 & 4.1 & 5.4 & 7.9 & 11.7 & 15.0 & 18.1 & 12.4 \\
\hline & Maán & Basta & ${ }^{\circ} 30 ' 13$ & ${ }^{\circ} 35^{\prime} 31$ & 160 & 1420 & 17.4 & 11.3 & 6.9 & 5.5 & 7.4 & 10.1 & 14.5 & 18.6 & 21.8 & 15.1 \\
\hline
\end{tabular}


(mEq) $100 \mathrm{~g}^{-1}$, and electrical conductivity (1:1) of $0.4 \mathrm{dS} \mathrm{m}^{-1}$.

The experiment was conducted under well watered (continuous irrigation at $90 \%$ of available water) and droughted conditions (continuous water stress at $30 \%$ of available water) in two successive seasons (2005/2006 and 2006/2007). The experimental design was a split-plot design in randomized complete block. Water treatments were the main plot and barley lines and two check varieties were the sub-plot factor. The experiment included two replications. Each line within a replicate was represented by five healthy seedlings. On December $1^{\text {st }}$ barley seeds were sown in the plastic pots at a rate of 10 seeds per pot. Diammonium phosphate (DAP) was applied at a rate of $0.4 \mathrm{~g}$ per pot (equivalent to $100 \mathrm{~kg} \mathrm{ha}^{-1}$ ) at planting date. All pots were irrigated to field capacity from seeding time until emergence and then seedlings were thinned to five healthy seedlings per pot at the 2-3 leaf stage.

\subsection{Parameters recorded}

Data were collected for seven main agronomic traits; namely, plant height at maturity $(\mathrm{cm}$; from soil surface to tip of spike excluding awns), grain yield $\left(\mathrm{g}\right.$ plant $\left.{ }^{-1}\right)$, biological yield $\left(\mathrm{g}\right.$ plant $\left.{ }^{-1}\right)$, straw yield $\left(\mathrm{g}\right.$ plant ${ }^{-1}$ calculated as a difference between biological yield and grain yield), yield components including number of fertile tillers, number of spikes plant ${ }^{-1}$ and one hundred kernels weight $(\mathrm{g})$. Moreover, two phenological traits were recorded, i.e. days to heading from emergence $(50 \%$ of spikes fully emerged from flag leaf) and days to maturity from emergence (50\% of peduncles turned yellow).

\subsection{Biometrical analysis}

Heritability was estimated using combined analysis of variance across the experiments and the water treatments. Analysis of variance was performed by applying the following mathematical model (Steel and Torrie, 1980): $\mathrm{y}_{\mathrm{ijk}}=\mu+\mathrm{E}_{\mathrm{i}}+\mathrm{B}_{\mathrm{j}}+\mathrm{N}_{\mathrm{k}}+\mathrm{G}_{1}+\mathrm{EG}_{\mathrm{il}}+\mathrm{BG}_{\mathrm{jl}}+\mathrm{NG}_{\mathrm{kl}}$ $+\mathrm{EBG}_{\mathrm{ijl}}+\mathrm{BNG}_{\mathrm{jkl}}$, where $\mathrm{y}_{\mathrm{ijkl}}$ represents the observation from the $\mathrm{ijkl}{ }^{\text {th }}$ (experimental unit) plot, $\mu$ is the overall mean, $E_{i}$ is the effect of $i^{\text {th }}$ independent experiment, $B_{j}$ is the effect of $j^{\text {th }}$ block, $\mathrm{N}_{\mathrm{k}}$ is the effect of $\mathrm{k}^{\text {th }}$ water level, $\mathrm{G}_{1}$ is the effect of $1^{\text {th }}$ line, $\mathrm{EG}_{\mathrm{il}}$ is the interactive effect of $\mathrm{i}^{\text {th }}$ experiment with $1^{\text {th }}$ line, $\mathrm{BG}_{\mathrm{j} 1}$ is the interaction effect of $1^{\text {th }}$ line with $j^{\text {th }}$ block, $\mathrm{NG}_{\mathrm{kl}}$ is the interactive effect of $\mathrm{k}^{\text {th }}$ water treatment with $1^{\text {th }}$ line, $\mathrm{EBG}_{\mathrm{ijl}}$, is the interactive effect of $\mathrm{l}^{\text {th }}$ line with $\mathrm{j}^{\text {th }}$ block in $\mathrm{i}^{\text {th }}$ experiment, $B N \mathrm{~B}_{\mathrm{jkl}}$ is the interactive effect of $1^{\text {th }}$ line with $\mathrm{k}^{\text {th }}$ water treatment in $\mathrm{j}^{\text {th }}$ block. The form of analysis of variance and the expected mean square (MS) are presented in Table 2a (Hallauer and Miranda, 1988). Variance components were calculated from expected mean squares (across experiments and water treatments) as follows:

$\sigma_{e}^{2}=M_{e}$

$$
\begin{aligned}
& \sigma_{g \times e x \times w t}^{2}=\frac{M_{g \times e x \times w t}-M_{e}}{r} \\
& \sigma_{g \times w t}^{2}=\frac{M_{g \times w t}-M_{e}}{r \times l} \\
& \sigma_{g \times e x}^{2}=\frac{M_{g \times e x}-M_{e}}{r \times n} \\
& \sigma_{g}^{2}=\frac{M_{g}-M_{g \times e x}-M_{g \times w t}+M_{g \times e x \times w t}}{r \times l \times n}
\end{aligned}
$$

Where $M_{g}, M_{g \times e x}, M_{g \times w t}, M_{g \times e x \times w t}$ and $M e$ are the mean squares of lines, line $\times$ experiment interaction, line $\times$ water treatment interaction, line $\times$ experiment $\times$ water treatment interaction and pooled error, and $\mathrm{l}, \mathrm{n}$, and $\mathrm{r}$ denote the number of experiments, water treatments and replications, respectively.

From combined analyses of variance over water treatments and experiments, broad sense heritability $\left(h_{c}^{2}\right)$ was calculated on an entry mean basis as described by Hallauer and Miranda (1988) as follows:

$h_{c}^{2}=\frac{\sigma_{g}^{2}}{\sigma_{g}^{2}+\sigma_{g \text { XeX }}^{2} / l+\sigma_{g \text { Xwt }}^{2} / n+\sigma_{g \text { X } \mathrm{XXXwt}}^{2} / \ln +\sigma_{\mathrm{B}}^{2} / \ln r}$

Where, $\sigma_{g}^{2}$ is the line (genotypic) variance, $\sigma_{g \times \operatorname{ex}}^{2}$ is the line $\times$ experiment interaction component of the variance, $\sigma_{g \times w t}^{2}$ is line $\times$ water treatment component of variance, $\sigma_{g \times e \times \times w t}^{2}$ is line $\times$ experiment $\times$ water treatment interaction component of variance, and $\sigma_{a}^{2}$ is the error variance.

Analysis of variance was also performed separately under well watered and drought stress conditions using randomized complete block design (RCBD) by applying the following mathematical model (Steel and Torrie, 1980):: $\mathrm{y}_{\mathrm{ijk}}=\mu+\mathrm{E}_{\mathrm{i}}+\mathrm{B}_{\mathrm{j}}+\mathrm{G}_{\mathrm{k}}+\mathrm{EG}_{\mathrm{ik}}+\mathrm{BG}_{\mathrm{jk}}+\mathrm{EBG}_{\mathrm{ijk}}$, where $y_{i j k}$ represents the observation from the $i \mathrm{jk}^{\text {th }}$ experimental unit (Plot), $\mu$ is the ground mean, $E_{i}$ is the effect of $i^{\text {th }}$ independent experiment, $B_{i}$ is the effect of $j^{\text {th }}$ replicate, $G_{k}$ is the effect of $k^{\text {th }}$ line, $E G_{i k}$ is the interactive effect of the $i^{\text {th }}$ experiment with $\mathrm{k}^{\text {th }}$ line, $\mathrm{BG}_{\mathrm{jk}}$ is the interactive effect of $\mathrm{j}^{\text {th }}$ 
Table (2a): Form of variance analysis and mean square expectations models including the factors $\mathrm{g}=$ line, $\mathrm{wt}=\mathrm{water}$ treatment and ex $=$ experiment, for trials in a randomized complete block design (i.e. wt and ex were crossed factors)

\begin{tabular}{|c|c|c|c|}
\hline Source & $\begin{array}{l}\text { Degree of } \\
\text { freedom }(\mathrm{df})\end{array}$ & Mean square & Expected mean square \\
\hline Line (g) & g-1 & $M_{g}$ & $\sigma_{e}^{2}+r \cdot \sigma_{g \times e x \times w t}^{2}+r \cdot e x \cdot \sigma_{g \times w t}^{2}+r . w t . \sigma_{g \times e x}^{2}+r \cdot e x \cdot w t . \sigma_{g \times e x \times w t}^{2}$ \\
\hline Line $\times$ Water treatment $(g \times w t)$ & $(-1)(n-1)$ & $M_{g \times w t}$ & $\sigma_{e}^{2}+r \cdot \sigma_{g \times e x \times \omega t}^{2}+r \cdot e x \cdot \sigma_{g \times w t}^{2}$ \\
\hline Line $\times$ Experiment $(\mathrm{g} \times \mathrm{ex})$ & $(\mathrm{g}-1)(\mathrm{l}-1)$ & $M_{g \times e x}$ & $\sigma_{e}^{2}+r . \sigma_{g \mathrm{Xex} \times w t}^{2}+r . w t . \sigma_{g \mathrm{X} e x}^{2}$ \\
\hline $\begin{array}{l}\text { Line } \times \text { Water treatment } \times \text { Experiment }(\mathrm{g} \times \mathrm{wt} \times \\
\mathrm{ex})\end{array}$ & $(\mathrm{g}-1)(\mathrm{n}-1)(\mathrm{l}-1)$ & $M_{g \times w t \times e x}$ & $\sigma_{\theta}^{2}+r \cdot \sigma_{g \mathrm{Xex} \times w t}^{2}$ \\
\hline Error & $\mathbf{n}(\mathrm{g}-1)(\mathbf{l}-1)$ & $M_{e}$ & $\sigma_{\theta}^{2}$ \\
\hline
\end{tabular}

$\mathrm{g}, \mathrm{l}, \mathbf{n}$ and $\mathbf{r}$ (in df column) denote number of lines, number of experiments, number of water treatments and number of replications, respectively

Table (2b): Form of variance analysis and mean square expectation models including the factors $\mathrm{g}=$ line and $\mathrm{ex}=$ experiment, for trials in a randomized complete block design (i.e. ex was crossed factor).

\begin{tabular}{|l|l|l|l|}
\hline Source & Degree of freedom $(\mathbf{d f})$ & Mean square & Expected mean square \\
\hline Line $(\mathrm{g})$ & $\mathrm{g}-1$ & $M_{g}$ & $\sigma_{\theta}^{2}+r \cdot \sigma_{g \times e x}^{2}+r \cdot e x \cdot \sigma_{g}^{2}$ \\
\hline Line $\times$ Experiment $(\mathrm{g} \times \mathbf{e x})$ & $(\mathrm{g}-1)(\mathrm{ex}-1)$ & $M_{g \times e x}$ & $\sigma_{\theta}^{2}+r \cdot \sigma_{g \times e x}^{2}$ \\
\hline Error & $\mathrm{g} \times \mathrm{wt}(\mathbf{r}-1)$ & $M_{e}$ & $\sigma_{\theta}^{2}$ \\
\hline
\end{tabular}

$\mathrm{g}, \mathrm{I}$ and $\mathbf{r}$ (in df column) denote number of lines, number of experiments and number of replications, respectively 
replicate with $\mathrm{k}^{\text {th }}$ genotype and $\mathrm{EBG}_{\mathrm{ijk}}$ is the experimental error. The form of analysis of variance and the expected mean square (MS) are presented in Table 2b (Hallauer and Miranda, 1988). Thereafter, variance components were calculated from expected mean squares (across experiments) as follows:

$\sigma_{e}^{2}=M_{e}$

$\sigma_{g \times e x}^{2}=\frac{M_{g \times e x}-M_{e}}{r}$

$\sigma_{g}^{2}=\frac{M_{g}-M_{g \times e x}}{r \times l}$

The variance components due to lines $\left(\sigma_{g}^{2}\right.$ or genetic variance), genotype $\times$ experiment variance $\left(\sigma_{g \times E x}^{2}\right)$, and error variance $\left(\sigma_{\Theta}^{2}\right)$ were estimated according to Hallauer and Miranda (1981). The phenotypic variance was calculated as: $\sigma_{p}^{2}=\sigma_{g}^{2}+\frac{\sigma_{g \times a x}^{2}}{n}+\frac{\sigma_{g}^{2}}{m}$, where ' $r$ ' is the number of replicates and ' $n$ ' is the number of experiments. An estimate of the broad-sense heritability $\left(h_{s}^{2}\right)$ was calculated as the ratio of the genetic $\left(\sigma_{g}^{2}\right)$ to the phenotypic $\left(\sigma_{p}^{2}\right)$ variances.

Expected genetic advance (GA) and GA as a percentage of the mean assuming selection of the superior $5 \%$ of the genotypes were estimated in accordance with the methods illustrated by Fehr (1987):

$$
\begin{aligned}
& G A=i \sqrt{\sigma_{p}^{2}} h^{2} \\
& \text { GA\% ( } G A \text { as a pecentage of mean) }=\frac{G A}{\bar{X}} \times 100 \%
\end{aligned}
$$

Where, $i$ is a selection differential which at a selection intensity of $5 \%$ (is 2.06), $\sqrt{\sigma_{p}^{2}}$ is the phenotypic standard deviation and $h^{2}$ is the heritability estimat.

Principal component analysis (PCA) is appropriate when obtained measures on a number of variables and wish to develop a smaller number of artificial variables (called principal components) that will account for most of the variance in the observed variables (Jolliffe, 2002). Consequently, the principal components may then be used to identify the major traits accounting for most of the gross variation among the studied inbred lines. To avoid effects owing to scaling differences, the mean of each character was normalized prior to principle component analysis (PCA) using Z-scores. PCA was performed to identify the major traits accounting for most of the gross variation among the studied inbred lines. Correlation coefficients were estimated to assess the interrelationships among different agronomic traits under well watered and drought conditions. In order to identify superior lines which exceeded the value of the best standard check, the differences between the means were compared using least significant difference (LSD) at $\mathrm{P}$ $\leq 0.05$. All statistical computations were performed with the computer program PLABSTAT (Utz, 2000).

\section{RESULTS \\ 3.1. Ranges and coefficients of variation for studied traits}

The mean, range, coefficient of variation and analysis of variance combined across experiments and water treatments for nine traits of 165 barley lines are presented in Table 2. Most studied traits showed wider ranges under well watered conditions than under drought, except for days to heading and number of tillers which remained relatively constant (Table 3). Lines required 97 to 118 days to reach heading and showed tillers number ranging from 1 to 9 under both conditions.

Under well watered conditions, line mean values for plant height ranged from 48.3 to 121.8 $\mathrm{cm}$ and days to maturity ranged from 136.5 to 154.3 days. Grain yield, straw yield and biological yield ranged from 0.48 to $4.57 \mathrm{~g} \mathrm{plant}^{-1}$, from 2.27 to $11.1 \mathrm{~g} \mathrm{plant}^{-1}$ and from 5.42 to $17.3 \mathrm{~g} \mathrm{plant}^{-1}$, respectively. Number of kernels spike ${ }^{-1}$ ranged from 1.42 to 32.5 , while the weight of one hundred kernels ranged from 2.52 to $7.88 \mathrm{~g}$.

Under drought, plant height and days to maturity ranged from 25.8 to $68.3 \mathrm{~cm}$ and from 132.8 to 141.0 days, respectively. Grain yield ranged from less than $0.1 \mathrm{~g} \mathrm{plant}^{-1}$ to $3.78 \mathrm{~g}_{\text {plant }}$ 1 , and straw yield and biological yield showed ranges extended from 0.58 to $8.78 \mathrm{~g}$ plant $^{-1}$ and from 1.61 to $14.24 \mathrm{~g}$ plant $^{-1}$, respectively. Number of kernels spike ${ }^{-1}$ and one hundred kernels weight showed ranges from 0.45 to 24.97 and from 1.02 to $7.64 \mathrm{~g}$, respectively. Days to maturity were accelerated by 10 days in response to droughted conditions. Significant reductions $(P \leq 0.01)$, due to drought treatment were observed in the remaining parameters, except days to heading and number of tillers. The reductions in plant height and grain yield were 39.84 and $56.0 \%$, respectively. Numbers of kernels per spike and one hundred kernel weight were the main contributors for grain yield losses (reductions= 41.73 and $32.72 \%$, respectively). Losses in straw yield and biological yield were 21.22 and $32.22 \%$, 
Table (3): Ranges, means and coefficient of variation (CV\%) under well watered and drought stress conditions for the 9 agronomic traits in the 165 barley lines.

\begin{tabular}{|c|c|c|c|c|c|c|c|c|c|c|}
\hline \multirow{2}{*}{ Trait } & \multicolumn{4}{|c|}{ Well watered } & \multicolumn{4}{|c|}{ Drought stress } & \multirow{2}{*}{$\begin{array}{c}\% \text { of } \\
\text { reductions }\end{array}$} & \multirow{2}{*}{$\begin{array}{l}\text { F-value for } \\
\text { water treatment }\end{array}$} \\
\hline & Min & Max & Mean & C.V.\% & Min & Max & Mean & C.V.\% & & \\
\hline Plant height (cm) & 48.3 & 121.8 & 79.0 & 14.3 & 25.8 & 68.3 & 47.53 & 16.79 & 39.84 & $* *$ \\
\hline Days to heading & 97.8 & 117.3 & 103.4 & $\mathbf{3 . 3 3}$ & 97.00 & 118.0 & 103.63 & 2.99 & -0.22 & ns \\
\hline Days to maturity & 136.5 & 154.3 & 145.8 & 2.36 & 132.8 & 141.0 & 134.65 & 1.89 & 7.65 & $*$ \\
\hline Grain yield per plant (g) & 0.48 & 4.57 & 2.5 & 31.36 & 0.08 & 3.78 & 1.10 & 57.88 & 56.00 & $* *$ \\
\hline Straw yield per plant (g) & 2.27 & 11.1 & 4.9 & 28.08 & $\mathbf{0 . 5 8}$ & 8.78 & 3.86 & 32.29 & 21.22 & $* *$ \\
\hline Biological yield per plant (g) & 5.42 & $\mathbf{1 7 . 3}$ & 10.8 & 20.71 & 1.61 & 14.24 & 7.32 & 26.90 & 32.22 & $* *$ \\
\hline Number of tillers & $\mathbf{0 . 8 2}$ & 9.20 & 4.13 & 33.62 & 1.65 & 8.43 & 4.31 & 27.61 & -4.36 & ns \\
\hline Number of kernels per spike & 1.42 & 32.5 & 11.79 & 36.48 & $\mathbf{0 . 4 5}$ & 24.97 & 6.87 & 51.06 & 41.73 & $* *$ \\
\hline One hundred seeds weight (g) & 2.52 & 7.88 & 5.93 & 18.01 & 1.02 & 7.64 & 3.99 & 30.80 & 32.72 & $* *$ \\
\hline
\end{tabular}

*Significant at $P<0.05$; **significant at $P<0.01$; ns-non significant

Table (4): Estimates of variance components and broad sense heritability $\left(h_{e}^{2}\right)$, for the 9 agronomic traits in the 165 barley lines combined across experiments and water treatments.

\begin{tabular}{|c|c|c|c|c|c|c|}
\hline \multirow[b]{2}{*}{ Trait } & \multicolumn{5}{|c|}{ Variance Components } & \multirow[b]{2}{*}{$h_{c}^{2}$} \\
\hline & Lines & $\begin{array}{c}\text { Lines } \times \\
\text { experiment }\end{array}$ & $\begin{array}{l}\text { Lines } \times \text { drought } \\
\text { stress treatment }\end{array}$ & $\begin{array}{c}\text { Lines } \times \text { Experiment } \\
\times \text { drought stress } \\
\text { treatment }\end{array}$ & Error & \\
\hline Plant height (cm) & $90.42 * *$ & $10.5 * *$ & $109.0 * *$ & 47.25 & 524.99 & 0.54 \\
\hline Days to heading & $120.99 * *$ & 1.81 & $101.9 * *$ & 54.86 & 1448.4 & 0.62 \\
\hline Days to maturity & $341.03 * *$ & $5.02 *$ & $157.08 * *$ & 57.86 & 2668.2 & 0.76 \\
\hline Grain yield per plant (g) & $117.61 * *$ & 2.361 & $177.1 * *$ & $\mathbf{1 3 2 . 5 8}$ & 613.94 & 0.46 \\
\hline Straw yield per plant (g) & $625.8 * *$ & 5.927 & $1061.79 * *$ & 313.4 & 8203.7 & 0.49 \\
\hline Biological yield per plant (g) & $641.4^{* * *}$ & 7.12 & $609.8 * *$ & 1431 & 5092.5 & 0.43 \\
\hline Number of tillers & $182.58 * *$ & $6.27 *$ & $142.87 * *$ & 323.04 & 1266.7 & 0.48 \\
\hline Number of kernels per spike & $0.636 * *$ & 0.00314 & $1.737 * *$ & 0.641 & 3.12 & 0.36 \\
\hline One hundred seeds weight (g) & $208.61 * *$ & $17.16 * *$ & $106.1 * *$ & 403.59 & 1473.5 & 0.49 \\
\hline
\end{tabular}

* Significant at $P<0.05 ; * *$ significant at $P<0.01$ 
respectively.

The coefficient of variation $(\mathrm{CV})$ values were extremely low $(<4 \%)$ for days to heading and days to maturity. Grain yield plant ${ }^{-1}$ and number of kernels spike $^{-1}$ showed high CV value under drought (57.88 and $51.06 \%$, respectively) and intermediate value under well watered conditions (31.36 and $36.48 \%$, respectively). Plant height showed comparatively low CV values under well watered conditions $(14.3 \%)$ but showed upward estimates under drought (39.84\%). The remaining traits exhibited $\mathrm{CV}$ values ranging from 18.0 to $33.62 \%$ under well watered conditions and from 27.61 to $32.29 \%$ under drought conditions.

\subsection{Variance components and heritability estimates}

Combined analysis of variance across experiments and water treatments showed significant $(\mathrm{P}<0.01)$ genetic variation on all tested parameters studied (Table 4). Water treatments and lines interacted significantly $(\mathrm{P}<0.0)$ for all tested agronomic traits, while variance due to lines $x$ experiment interaction was much lower for all traits although significant in some cases. Across traits, days to heading and days to maturity showed relatively high $h_{c}^{2}$ values $\left(h_{c}^{2}=0.62\right.$ to 0.76 , respectively), whereas other traits showed comparatively intermediate values (range $=0.36$ to $0.54)$.

Estimates of $h_{s}^{2}$, phenotypic variance and GA expected from selecting the superior 5\% of lines for each trait computed using the variance components based on the combined analyses across the two experiments under well watered and drought stress are presented in Tables (5 and $6)$. Variance components for lines were extremely higher than those for line $x$ experiment interactions. Nevertheless, line $x$ experiment interaction components for days to heading was significant $(\mathrm{P}<0.05)$ at both water treatments and for number of kernels spike ${ }^{-1}$ only under drought conditions. $h_{s}^{2}$ estimates under well watered conditions for plant height, days to heading and days to maturity ( $h_{s}^{2}$ ranged from 0.75 to 0.83 ) were high, while respective estimates were moderate for grain yield, biological yield and yield components, ranging from 0.61 to 0.73 . In the current study, the magnitude of $h_{s}^{2}$ showed upward estimates under well watered than under drought conditions (Table 6). Under droughted conditions, $h_{s}^{2}$ estimates were low for grain yield, straw yield, number of tillers and one hundred kernels weight ( $h_{s}^{2}$ ranged from 0.38 to 0.43 ) but moderate for other traits $\left(h_{s}^{2}\right.$ ranged from 0.49 to
$0.58)$.

\subsection{Expected genetic advance}

In general, high genetic advance (GA) was associated with high heritability values under well watered treatment. Under well watered treatment, days to heading and days to maturity showed low GA values of 2.35 and $2.87 \%$, respectively, while GA was $86.06,38.66$ and $41.11 \%$ for grain yield, straw yield and biological yield, respectively. Yield components showed GA expectations between $36.07 \%$ for number of tillers to $84.55 \%$ for number of kernels per spike.

Under drought conditions, six traits (grain yield, biological yield, straw yield and yield components) showed relatively lower GA\% than that observed at well watered conditions, ranging from $6.83 \%$ for plant height to $21.09 \%$ for biological yield. Similarly, days to heading and days to maturity showed GA\% values more or less similar to those obtained under well watered conditions (GA $=1.17$ and $3.78 \%$, respectively).

\subsection{Correlations between traits}

Phenotypic correlation coefficients among the studied traits under well watered and drought conditions are presented in (Table 7). The correlation between grain yield and biological yield was positive and highly significant under well watered conditions $(\mathrm{r}=0.72 * *)$ and positive but weak under drought conditions $\left(\mathrm{r}=0.25^{* *}\right)$. Moreover, grain yield under well watered and drought conditions was positively associated with number of tillers $(\mathrm{r}=0.22 * *$ and $0.21 * *$, respectively) and number of kernels per spike $\left(\mathrm{r}=0.30^{* *}\right.$ and $0.70^{* *}$, respectively), but showed only a positive correlation with one hundred kernel weight under drought $(\mathrm{r}=0.47 * *)$. Number of kernels spike ${ }^{-1}$ exhibited a weak negative association with one hundred kernels weight under well watered condition $(\mathrm{r}=-0.24 * *)$ and with number of tillers under drought $\left(\mathrm{r}=-0.25^{* *}\right)$. Other correlations among yield components were not significant. The correlation between days to heading and days to maturity was positive and significant under drought conditions $\left(\mathrm{r}=0.38^{* *}\right)$.

\subsection{Principal component analysis}

The first three components explained 64.86 and $67.49 \%$ of the total variation contributed by all traits under well watered and drought conditions, respectively (Table 8). The first component explained 30.22 and $28.22 \%$ of the variation and with high loading on straw yield, biological yield and number of tillers under well watered treatment and mainly by grain yield under drought. The second component accounted for 21.55 and $25.08 \%$ of the total variation under well 
Table (5): Estimates of variance components and broad sense heritability $\left(h_{s}^{2}\right)$, for the 9 agronomic traits in the 165 barley lines combined across experiments under well watered conditions.

\begin{tabular}{|c|c|c|c|c|c|c|c|}
\hline \multirow[t]{2}{*}{ Trait } & \multicolumn{3}{|c|}{$\begin{array}{l}\text { Variance components/well } \\
\text { watered }\end{array}$} & \multirow[b]{2}{*}{$h_{s}^{2}$} & \multirow[t]{2}{*}{$\begin{array}{l}\text { Phenotypic } \\
\text { variance } \\
\text { (PV) }\end{array}$} & \multirow[t]{2}{*}{$\begin{array}{c}\text { Genetic } \\
\text { advance } \\
\text { (GA) }\end{array}$} & \multirow[t]{2}{*}{ GA\% } \\
\hline & Lines & $\begin{array}{c}\text { Lines } \times \\
\text { Experiment }\end{array}$ & Error & & & & \\
\hline Plant height (cm) & $90.5 * *$ & 1.07 & 70.90 & $\mathbf{0 . 8 3}$ & 108.76 & $\mathbf{1 7 . 8 8}$ & 37.61 \\
\hline Days to heading & $1.78 * *$ & 0.066 & 1.80 & 0.79 & 2.26 & 2.44 & 2.35 \\
\hline Days to maturity & $4.73 * *$ & 0.072 & 6.33 & 0.75 & 6.35 & 3.87 & 2.87 \\
\hline Grain yield per plant (g) & $0.319 * *$ & 0.0088 & 2.08 & 0.66 & 0.48 & 0.95 & 86.06 \\
\hline Straw yield per plant (g) & $0.86 * *$ & 0.028 & 2.14 & 0.61 & 1.41 & 1.49 & 38.66 \\
\hline Biological yield per plant(g) & $2.93 * *$ & 0.079 & 0.63 & 0.73 & 4.02 & 3.01 & 41.11 \\
\hline Number of tillers & $0.903 * *$ & 0.019 & 4.22 & 0.63 & 1.43 & 1.55 & 36.07 \\
\hline Number of kernels per spike & $10.97 * *$ & $0.13 *$ & 6.63 & 0.72 & 15.14 & 5.81 & 84.55 \\
\hline Hundred seed weight (g) & $3.35 * *$ & 0.121 & 0.00 & 0.66 & 5.07 & 3.07 & 76.84 \\
\hline
\end{tabular}

* Significant at $P<0.05 ; * *$ significant at $P<0.01$

Table (6): Estimates of variance components and broad sense heritability $\left(h_{s}^{2}\right)$, for 9 agronomic traits in 165 barley lines combined over experiments under drought stress treatment.

\begin{tabular}{|c|c|c|c|c|c|c|c|}
\hline \multirow[t]{2}{*}{ Trait } & \multicolumn{3}{|c|}{ Variance components/drought stress } & \multirow[b]{2}{*}{$h_{s}^{2}$} & \multirow{2}{*}{$\begin{array}{c}\text { Phenotypic } \\
\text { variance } \\
(\mathrm{PV}) \\
\end{array}$} & \multirow{2}{*}{$\begin{array}{l}\text { Genetic } \\
\text { advance } \\
\text { (GA) }\end{array}$} & \multirow[t]{2}{*}{ GA\% } \\
\hline & Lines & Lines $\times$ Experiment & Error & & & & \\
\hline Plant height (cm) & $14.27 * *$ & 1.479 & 58.60 & 0.48 & 29.66 & 5.40 & 6.83 \\
\hline Days to heading & $6.22 * *$ & $1.96 *$ & 14.22 & 0.58 & 10.76 & 3.91 & 3.78 \\
\hline Days to maturity & $1.38 * *$ & 0.2026 & 5.27 & 0.49 & 2.80 & 1.70 & 1.17 \\
\hline Grain yield per plant (g) & $0.102 * *$ & $\mathbf{0 . 0 1 2 3}$ & 1.19 & 0.38 & 0.27 & 0.41 & 16.21 \\
\hline Straw yield per plant $(g)$ & $0.42 * *$ & $\mathbf{0 . 0 5 3}$ & 2.40 & 0.40 & $\mathbf{1 . 0 5}$ & $\mathbf{0 . 8 5}$ & $\mathbf{1 7 . 2 6}$ \\
\hline Biological yield per plan $(\mathrm{g}) \mathrm{t}$ & $2.24 * *$ & 0.24 & 0.64 & 0.55 & 4.11 & 2.28 & 21.09 \\
\hline Number of tillers & $0.239 * *$ & 0.14 & 6.98 & 0.39 & 0.61 & 0.63 & 15.29 \\
\hline Number of kernels per spike & $2.66 * *$ & $0.73 *$ & 2.56 & $\mathbf{0 . 5 3}$ & 5.02 & 2.45 & 20.75 \\
\hline One hundred seeds weight (g) & 0.38** & 0.025 & 0.01 & 0.43 & 1.03 & 0.77 & 12.98 \\
\hline
\end{tabular}

* Significant at $P<0.05$; ** significant at $P<0.01$ 
Table (7): Phenotypic correlation coefficients among various pairs of the 9 agronomic traits in 165 barley lines under well watered (above diagonal) and drought (below diagonal) treatment.

\begin{tabular}{|c|c|c|c|c|c|c|c|c|c|c|}
\hline No. & Trait & 1 & 2 & 3 & 4 & 5 & 6 & 7 & 8 & 9 \\
\hline 1 & Plant height (cm) & & -0.14 & $-0.26 * *$ & $\mathbf{0 . 0 7}$ & $-0.16 *$ & -0.07 & $-0.41 * *$ & $0.38 * *$ & $\mathbf{0 . 0 8}$ \\
\hline 2 & Days to heading & $\mathbf{0 . 0 5}$ & & $\mathbf{0 . 0 8}$ & $-0.17 *$ & 0.09 & -0.07 & 0.18** & $-0.20 *$ & 0.18* \\
\hline 4 & Grain yield per plant (g) & $0.37 * *$ & $-0.21 * *$ & $-0.34 * *$ & & $\mathbf{0 . 0 3}$ & 0.72** & $\mathbf{0 . 2 2} * *$ & $.30 * *$ & $\mathbf{0 . 1 3}$ \\
\hline 5 & Straw yield per plant (g) & -0.04 & -0.02 & $\mathbf{0 . 1 0}$ & $-0.16 *$ & & $0.65 * *$ & $0.56 * *$ & $-0.31 * *$ & -0.07 \\
\hline 6 & Biological yield per plant (g) & $\mathbf{0 . 1 0}$ & -0.12 & -0.05 & $0.25 * *$ & $0.91 * *$ & & $0.57 * *$ & $.30 * *$ & 0.13 \\
\hline 8 & Number of kernels per spike & $\mathbf{0 . 3 1} * *$ & -0.07 & $-0.28 * *$ & 0.70** & $-0.32 * *$ & -0.04 & $-0.25 * *$ & & $-0.24 * *$ \\
\hline 9 & One hundred seed weight (g) & $0.22 * *$ & $-0.31 * *$ & $-0.25 * *$ & $0.47 * *$ & -0.13 & 0.08 & -0.11 & 0.04 & \\
\hline
\end{tabular}

Table (8): Correlation coefficients among the 9 agronomic traits and the first three principal components in the 165 barley lines.

\begin{tabular}{|c|c|c|c|c|c|c|}
\hline \multirow{2}{*}{ Trait } & \multicolumn{3}{|c|}{ Components/well watered } & \multicolumn{3}{|c|}{ Components/drought stress } \\
\hline & 1 & 2 & 3 & 1 & 2 & 3 \\
\hline Plant height (cm) & -0.496 & 0.416 & 0.034 & 0.494 & 0.216 & 0.434 \\
\hline Days to heading & 0.199 & -0.420 & -0.364 & -0.388 & -0.197 & $\underline{0.741}$ \\
\hline Days to maturity & 0.286 & -0.374 & 0.167 & -0.603 & -0.153 & $\overline{0.320}$ \\
\hline Grain yield per plant (g) & 0.274 & 0.829 & 0.091 & 0.814 & 0.351 & 0.244 \\
\hline Straw yield per plant (g) & 0.759 & 0.102 & -0.129 & -0.449 & $\underline{0.820}$ & -0.078 \\
\hline Biological yield per plant (g) & $\underline{0.726}$ & 0.657 & -0.036 & -0.105 & 0.950 & 0.000 \\
\hline Number of tillers & 0.904 & -0.053 & -0.067 & -0.211 & 0.647 & 0.260 \\
\hline Number of kernels per spike & -0.598 & 0.561 & -0.360 & 0.737 & -0.067 & 0.404 \\
\hline One hundred seeds weight (g) & -0.015 & 0.059 & 0.925 & 0.564 & 0.165 & -0.375 \\
\hline$\%$ of variance & 30.22 & 21.55 & 13.09 & 28.22 & 25.08 & 14.19 \\
\hline
\end{tabular}


watered and drought conditions, respectively, and contributed by grain yield under well watered conditions and by straw yield and biological yield under drought conditions. The third component had the highest loading on one hundred kernels weight under well water conditions (13.09\%) and on days to heading under drought $(14.19 \%)$. The first component extracted in a principle component analysis accounts for maximal amount of total variance in the observed variables. This means that the first component should be correlated with straw yield, biological yield and number of tillers under well watered treatment and mainly with grain yield under drought. The second component extracted will have three important traits (i.e. grain yield under well watered conditions and by straw yield and biological yield under drought conditions). The second component will account for maximal amount of variance in the data set that is not accounted for by the first component. Since one hundred kernel weights under well watered conditions and days to heading under drought were present in the third component, they contributed less to the variability present among barley lines.

\subsection{Genotypic Performance}

Number and frequency of lines (\%) which exceeded the best standard check under well watered and drought stress, conditions are presented in (Table 9). One hundred and sixty three (163) and 40 lines were earlier in heading under optimum and water stress respectively. Forty seven (47) and 26 lines significantly $(\mathrm{P}<0.05)$ exceeded the tallest check cultivar RUM under well watered and drought conditions, respectively. From a total of 165 barley lines, the number of lines which significantly out-yielded the best standard check were $80(48.5 \%)$ and 98 $(59.4 \%)$ for grain yield, $7(4.2 \%)$ and $18(10.9 \%)$ for straw yield and $17(10.3 \%)$ and 31 (18.8\%) under well watered and drought conditions, respectively. The number of lines that significantly exceeded the values of the best checks for number of tillers and number of kernels spike $^{-1}$ were $10(6.1 \%)$ and $38(23.0 \%)$ and 132 $(80.0 \%)$ and $59(35.38 \%)$ under well watered and drought conditions, respectively. Seven lines $(4.2 \%)$ under well watered conditions and 54 lines (32.7\%) under drought conditions showed heavier kernels than the best check.

\section{DISCUSSION}

Improving yield is always a main target in plant breeding programs. The use of yield related traits is preferred by breeders as the inheritance of these traits might be less complicated than grain yield per se (Fehr, 1987). The information on the heritability and the relationships among characters is important for plant breeders to formulate appropriate breeding strategies. The final grain yield in barley is determined by yielding contributing traits (the number of spikes plant ${ }^{-1}$, number of grains per spike and grain weight). The existence of large level of variability in yield and yield contributed traits offers ample chances for the genetic improvement of the crop through selection and recombination of lines with desired expression. Similarly, high level of variability was reported in earlier studies among lines constituting landraces in barley (Jaradat et al., 2005), wheat (Ehdaie and Waines, 1989; Getachew et al., 1993 and Belay et al., 1993) and sesame (Bayder et al., 1999). In order to optimize the selection process of a breeding program, it is vital to estimate the magnitude of phenotypic and genotypic variability, heritability and genetic advance of the sources of genetic variation. The concept of heritability explains whether differences observed among lines are related to genetic make up or due to environmental conditions. Expected genetic advance gives an idea of possible improvement of new population from original population through selection of high performing line. From these perspectives, present investigation was undertaken to study the variability, heritability and genetic advance among barley lines originating from heterogeneous barley populations adapted to dry conditions.

Low grain yield to biological yield ratio in the current study was observed, which might be attributed to limited volume for root growth in the pots. However, values for grain yield and biological yield obtained in this study are within the range obtained by Haddadin (2009), who found mean values ranging from 2.17 to $4.68 \mathrm{~g}$ plant $^{-1}$ and from 5.0 to $7.49 \mathrm{~g}$ plant $^{-1}$ under optimum condition, and from 1.23 to $2.41 \mathrm{~g}$ plant $^{-1}$ and from 2.18 to $5.13 \mathrm{~g} \mathrm{plant}^{-1}$ under sustained water stress for grain yield and biological yield, respectively, in a study aimed at examining the response of 14 barley varieties to drought imposed at different developmental stages. Yield and yield related traits were significantly $(\mathrm{P}<0.01)$ reduced by imposing drought $(\mathrm{P}<0.01)$. One hundred kernel weight and number of kernels spike ${ }^{-1}$ were significantly $(\mathrm{P}<0.01)$ the main contributors to grain yield losses; however, the average number of tillers remains constant across water treatments. Earlier studies showed that drought stress treatments during the grain-filling period reduced 
grain yield by decreasing the number of fertile spikes and grains per plant (Samarh, 2004). Late drought stress decreased grain yield by decreasing the number of grains spike ${ }^{-1}$ and grain weight (Gonzalez et al., 1999 and Samarh, 2004). According to Garcia del Moral et al. (2003) the grain yield in barley depends mainly on spikes square meter ${ }^{-1}$ and number of kernels spike ${ }^{-1}$ and the effect of kernel weight on grain yield is negligible. More recently Haddadin (2009), found that grain yield under continuous irrigation was almost two times greater than under continuous drought treatment, while the reductions by imposing early and late drought were 12.9 and $26.1 \%$, respectively.

Line $x$ water treatment interaction was significant for most studied traits. The ranges were wider and mean values were higher for all characters in well watered conditions than values obtained under drought conditions. Such results indicate that these characters can be improved more easily under well watered conditions and the wide range values showed a higher number of lines with superior performance for yield and its components traits than the check varieties (Table 9). The considerable magnitude of genetic variability present in the base population of any crop species is pivotal to crop improvement which must be exploited by plant breeders for yield improvement. The high variations exhibited by grain yield, yield contributing traits and phenological traits indicate that Jordanian barley landraces are a potential source of variation for plant breeding programs. The variability contribution of these traits was further confirmed by high $\mathrm{CV}$ values and their high contribution to principal component scores. PCA analysis revealed that grain yield and yield components were responsible for most of the phenotypic variation, indicating that those traits are explaining most of the variation present among studied barley lines. The genetic variation was also reflected in the differences observed among the lines in response to water stress as revealed by high line $\times$ water treatment interaction. Similarly, a wide range of genotypic variation was detected in the large international barley collections (e.g. Ceccarelli et al., 1987; Weltzien, 1988; Weltzien and Fischbeck, 1990 and Jaradat et al., 2005). The results of these extensive screens led to identification of outstanding barley lines with high grain yield.

Results obtained in current study are confirming the previous results based on microsatellite data, which showed that Jordanian barley landraces are typically mixtures of homozygote genotypes (Abdel-Ghani et al., 2004 and Istaitie, 2005), pointing that Jordanian barley landraces exhibit high level of genetic variation within adapted genetic background. Selection of pure lines from heterogeneous barley populations is one of the easiest, oldest and cheapest methods for improving grain yield in self-pollinated crops. High proportion of the lines out-yielded the best check under optimum and water stress condition. Similarly, plant height, biological yield, straw yield and yield components for some lines showed higher performance than check varieties, which could indirectly used to improve grain and biomass yield. The methodology used in this study is similar to ICARDA's strategy previously used to release new varieties from heterogonous barley populations (Ceccarelli and Grando, 2000), which includes isolation of high-yielding pure lines from landraces as a new releases varieties after testing their stability across a wide range of environments. Such high yielding lines could be fairly exploited as parental lines in plant breeding programs to incorporate desirable characters and/or could be used to develop mixtures composed of pure lines superior for a set of agronomic characters. Mixing breeding lines could be used to enhance phenotypic stability and will conserve a certain amount of evolutionary process within populations (Einfeldt et al., 2005 and Abdel-Ghani et al., 2005). The existence of high level heterogeneity within landrace populations led to identification of high yielding genotypes from heterogeneous landrace populations locally grown by farmers in several self pollinated crops including barley (Weltzien, 1988 and Jaradat et al., 2004), wheat (Tesemma et al., 1993) and sesame (Bayder et al., 1999).

The magnitude of heritability was generally low to intermediate in all studied characters combined across experiments and water treatments for all agronomic traits recoded in this study. However, high genotype $\times$ water treatment interactions were recorded in this study, indicating that lines responded differently to water stress. Lower broad sence heritability could be attributed to the inclusion of non-heritable genetic variance and variance due to genotype $x$ environment interactions as compared to mono-environmental estimates (Falconer and Mackay, 1996). The high genotype $\times$ environment interactions could limit selection efficiency, since lines selected under near optimum growing conditions do not always perform well under poor conditions, and vice versa. Therefore, the most effective way to 
Table (9): Number (N) and frequency of lines which significantly exceeded the best standard check under well watered and drought stress conditions.

\begin{tabular}{|c|c|c|c|c|c|c|c|}
\hline Trait & Treatment & $\begin{array}{c}\text { No. of lines } \\
\text { tested }\end{array}$ & \multicolumn{2}{|c|}{ Means of checks } & \multirow[t]{2}{*}{$\mathbf{L S D}_{\mathbf{0 . 0 5}}$} & \multicolumn{2}{|c|}{$\begin{array}{c}\text { Number }(\mathrm{N}) \text { and } \\
\text { frequency }(\%) \text { of lines } \\
\text { significantly exceeding } \\
\text { the best check }\end{array}$} \\
\hline \multirow[b]{2}{*}{ Plant height (cm) } & \multirow[b]{2}{*}{ Well watered } & \multirow[b]{2}{*}{165} & RUM & ACSAD165 & & $\mathbf{N}$ & $\%$ \\
\hline & & & 78.25 & 67.5 & 8.03 & 47 & 28.5 \\
\hline & Drought & 165 & 47.25 & 46.25 & 8.56 & 26 & 15.8 \\
\hline \multirow{2}{*}{ Days to heading } & Well watered & 165 & 103.50 & 99.75 & 0.96 & 40 & 24.2 \\
\hline & Drought & 165 & 105.25 & 104.5 & 7.4 & 163 & 98.8 \\
\hline \multirow[t]{2}{*}{ Days to maturity } & Well watered & 165 & 154.25 & 151.75 & 0.99 & 165 & 100.0 \\
\hline & Drought & 165 & 133.0 & 140.75 & 0.72 & 90 & 54.5 \\
\hline \multirow[t]{2}{*}{ Grain yield plant $^{-1}(\mathrm{~g})$} & Well watered & 165 & 1.62 & 2.13 & 0.32 & 80 & 48.5 \\
\hline & Drought & 165 & 0.70 & 0.27 & 0.19 & 98 & 59.4 \\
\hline \multirow[t]{2}{*}{ Straw yield plant $^{-1}(\mathrm{~g})$} & Well watered & 165 & 4.88 & 7.05 & 0.62 & 7 & 4.2 \\
\hline & Drought & 165 & 2.91 & 4.34 & 0.99 & 18 & 10.9 \\
\hline \multirow[t]{2}{*}{ Biological yield plant $^{-1}(\mathrm{~g})$} & Well watered & 165 & 6.50 & 9.18 & 0.86 & 17 & 10.3 \\
\hline & Drought & 165 & 3.61 & 4.61 & 2.21 & 31 & 18.8 \\
\hline \multirow[t]{2}{*}{ Number of tillers } & Well watered & 165 & 4.31 & 6.09 & 0.47 & 10 & 6.1 \\
\hline & Drought & 165 & 4.32 & 3.54 & 0.78 & 38 & 23.0 \\
\hline \multirow[t]{2}{*}{ Number of kernels spike $^{-1}$} & Well watered & 165 & 6.45 & 6.48 & 2.04 & 132 & 80.0 \\
\hline & Drought & 165 & 4.87 & 3.88 & 2.21 & 59 & 35.8 \\
\hline \multirow[t]{2}{*}{ One hundred seeds weight (g) } & Well watered & 165 & 6.06 & 5.34 & 1.30 & 7 & 4.2 \\
\hline & Drought & 165 & 3.32 & 2.15 & 1.00 & 54 & 32.7 \\
\hline
\end{tabular}


improve the productivity of barley is to perform selection under targeted environments. Low heritability estimate and high genotype $x$ environment was observed in an earlier study conducted by Ceccarelli (1996) who reported that high grain yield under high input conditions and high grain yield in low input environments are under the control of different sets of alleles at most of the several loci that presumably control the grain yield. On the other hand, other earlier studies showed that selection under favorable conditions could produce lines suitable to both water limiting and water non-limiting environments (Arboleda-Rivera and Compton, 1974; Ceccarelli, 1987; Ceccarelli, 1989 and Virk and Mangant, 1991). However, some studies showed that direct selection for yield per se would be very effective strategy for barley improvement under rainfed conditions (Frey, 1964; Roy and Murty, 1970; Laing and Fisher, 1979; Chapman et al., 2000; Haussmann et al., 2000 and Ouk et al., 2006). Cross-over genotype $\times$ environment interaction can be observed in different crops under various types of stresses, in barley (Ceccarelli, 1989), wheat (Woodend and Glass, 1993), rice (Ouk et al., 2006), sorghum (Haussmann et al., 2000) and pearl millet (Virk and Mangat, 1991).

High heritability reflects the large heritable variance which may offer the possibility of improvement through selection (Barraiga, 1976). However, relying on the heritability values alone would not be practical to perform selection based on phenotypic appearance. Therefore, heritability estimates together with genetic advance are more important than heritability alone to predict the performance of selected lines (Johnson et al., 1955). In the present investigation, high heritability values coupled with high genetic advance were recorded for grain yield, plant biomass and yield components under well watered than under drought conditions. This might indicate the additive nature of genetic variation present among individuals constituting barley populations (Panse, 1957). High heritability accompanied by low genetic advance for phenological traits (days to heading and days to maturity) and plant height under drought conditions is an indicator of nonadditive gene action of the genetic variance, and this could lead to the conclusion that high heritability in phenological traits did not lead to increased genetic gain, because of insufficient genetic variability present for these traits (i.e. low CV and phenotypic variance) (Delogu et al, 1988; Sinha and Saha, 1999 and Sardana et al., 2007).
All yield components in this study had positive effects on grain yield under well watered and drought conditions, while days to heading and days to maturity which showed negative association effect on grain yield. Moreover, grain yield and yield contributing traits showed relatively high combinations of $h^{2}$ and GA. This could lead to the conclusion that selection of superior lines based on grain yield per se and/or indirect selection for yield contributing traits for improving the grain yield would be effective to improve grain yield and plant biomass. Selection for earliness (early heading and maturity) might be effective to improve grain yield under terminal drought stress. Earliness in barley might be able to avoid terminal drought stress. Earliness under drought stress will ensure that pollination and grain filling occur before heat and drought stress become too severe (Shakhatreh et al., 2001 and Samarah, 2004).

Barley landraces harbour great genetic variability for barley improvement. The present study revealed that there could be a lot of scope for the improvement of grain-yield using heterogeneous Jordanian barley landraces through direct selection of grain yield per se or by indirect selection for yield components. The characters like grain yield, biological yield and yield components exhibited high heritability values coupled with high genetic advance suggesting that selection of superior lines based on grain yield per se and/or indirect selection for yield components for improving the grain yield would be effective. However, heritability estimates and the magnitude of genetic advance, for yield and yield contributing traits under drought conditions was low in comparison to well watered conditions, which could be the most common justification for performing selection under well water conditions.

\section{REFERENCES}

Abdel-Ghani A.H., Parzies H.K., Ceccarelli S., Grando S. and Geiger H.H. (2005). Estimation of quantitative genetic parameters for outcrossing- related traits in barley. Crop Sci. 45:98-105.

Abdel-Ghani A. H., Parzies H.K., Omary A. and Geiger H.H. (2004). Estimating the outcrossing rate of barley landraces and wild barley populations collected from ecologically different regions of Jordan. Theor. Appl. Genet. 109:588-595.

Agorastos A.G. and Goulas C.K. (2005). Line selection for exploiting durum wheat $(T$. turgidum L. var. durum) local landraces in 
modern variety development program. Euphytica 146:117-124.

Arboleda-Rivera F. and Compton W.A. (1974). Differential response of maize (Zea mays L.) to mass selection in diverse selection environments. Theor. Appl. Genet. 44:137142.

Barraiga B.P. (1976). Variability and heritability of some quantitative characters in spring wheat. Agro. Sur. Chile 42:71-75.

Bayder H., Marquard R. and Turgut I. (1999). Pure line selection for improved yield, oil content and different fatty acid composition of sesame, Sesamum indicum. Plant Breeding 118: 462-464.

Belay G., Tesemma T., Becker H.C. and Merker A. (1993). Variation and interrelationships of agronomic traits in Ethiopian tetraploid wheat landraces. Euphytica 71:181-188.

Ceccarelli, S. (1987). Yield potential and drought tolerance of segregating populations of barley from contrasting environments. Euphytica 92:203-214.

Ceccarelli, S. (1989). Wide adaptation. How wide?. Euphytica 40:197-205.

Ceccarelli, S. (1996). Adaptation to low/high input cultivation conditions. Euphytica, 92:203-214.

Ceccarelli S. and Grando S. (1996). Drought as a challenge for the plant breeder. Plant Growth Regulators 20:149-155.

Ceccarelli S. and Grando S. (2000). Barley landraces from the Fertile Crescent: a lesson for plant breeders. In Genes in the Field: on-farm conservation of crop diversity, edited by Brush S. B., pp. 51-76. Lewis Publisher, Boca Raton; Fl, USA.

Ceccarelli S., Grando S. and van Leur J.A.G. (1987). Genetic diversity in barley landraces from Syria and Jordan. Euphytica 98:269-280.

Chapman S.C., Cooper M.C., Hammer G.L. and Butler D. (2000). Genotype by environment interactions affecting grain sorghum. II. Frequencies of different seasonal patterns of drought stress are related to location effects on hybrid yields. Aust. J. of Agr. Res. 51:209-222.

Delogu G.C., Larenoni Morocc A., Mortiniello P., Odoardi M. and Stance A. M. (1988). A recurrent selection programme for grain yield in winter barley. Euphytica 37:105110.

Ehdaie B. and Waines J.G. (1989). Genetic variation, heritability and path coefficient analysis in landraces of bread wheat from southwestern Iran. Euphytica, 41:183-190.

Einfeldt, C.H.P., Ceccarelli S., Grando S., GlandZwerger A. and Geiger H.H. (2005). Heterosis and mixing effects in barley under drought stress. Plant Breeding 24:350-355.

Falconer D.S. and Mackay T.F.C. (1996). Introduction to quantitative genetics, $4^{\text {th }}$ edition, Benjamin Cummings, England.

Fehr W.R. (1987). Breeding. In: Soybean physiology, agronomy and utilization (Ed. A.G. Norman), pp. 120-155, Academic Press, Inc. Ltd., London.

Forster B. (2004). Genotype and phenotype associations with drought tolerance in barley 14 tested in North Africa. Ann. Appl. Biol. 144, 157-168.

Frey K.J. (1964). Adaptation reaction of oat strains selected under stress and non-stress environmental conditions. Crop Sci. 4:5558.

Garcia del Moral L.F., Rharrabti Y., Villegas D. and Royo C. (2003). Evaluation of Grain Yield and Its Components in Durum Wheat under Mediterranean Conditions: An Ontogenic Approach. Agron. J. 95: 266274.

Getachew B., Tessema T., Becker H.C. and Merker A. (1993). Variation and interrelationships of agronomic traits in Ethiopian tetraploid wheat landraces. Euphytica 71:181-188.

Gonzalez A., Martin I. and Ayerbe L. (1999). Barley yield in waters tress conditions. The influence of precocity, osmotic adjustment and stomatal conductance. Field Crops Res. 62:23-34.

Haddadin M.F. (2009). Growth Performance of Some Barely Genotypes Subjected to Water Stress at Different Growth Stages. M.Sc Thesis, Mutah University, Karak, Jordan.

Hallauer A.R. and Miranda J.B. (1988). Quantitative Genetics in Maize Breeding, $2^{\text {nd }}$ Edn. Iowa State Univ. Press, Ames.

Hawkes, J.G. (1977). The importance of wild germplasm in plant breeding. Euphytica 26:615-621.

Haussmann B.I.G., Obilana A.B., Ayiecho P.O., Blum A., Schipprack W and Geiger, H.H. (2000). Yield and yield stability of four population types of grain sorghum in a semi-arid area of Kenya. Crop Sci. 40:319329.

Istaitie M. (2005). Genetic diversity of barley landraces and wild barley populations from 
Jordan. M. Sc. Thesis, University of Hohenheim, Institute of Plant Breeding, Seed Science and Population Genetics, Stuttgart, Germany.

Jaradat A.A. (1991). Levels of phenotypic variation for developmental traits in landraces genotypes of durum wheat (Triticum turgidum ssp. turgidum L. Conv. durum (Desf.) Mk.) from Jordan. Euphytica 51:265-271.

Jaradat A.A. (1992). Breeding potential of durum wheat landraces from Jordan II. Differential response to drought. Hereditas 116:305309.

Jaradat A.A., Shahid M. and Al Maskri A.Y. (2004). Genetic diversity in the Batini barley landrace from Oman II. Response to salinity stress. Crop Sci. 44:997-1007.

Jaradat A.A., Shahid M. and Al Maskri A.Y. (2005). Genetic diversity in the Batini barley landrace from Oman I. Spike and seed quantitative and qualitative traits. Crop Sci. 44:304-315.

Johanson H.W., Robinson H.F. and Comstock C.E. (1955). Estimates of genetic and environment variability in soybean. Agron. J. 47: 314-318.

Jolliffe, I.T. (2002). Principal component analysis. $2^{\text {nd }} E d$., Springer series of statistics.

Laing D.R. and Fisher R.A. (1979). Adaptation of semidwarf wheat cultivars to rainfed conditions. Euphytica 26:129-139.

Nevo E., Beiles A. and Ben-Shlomo R. (1984). The evolutionary significance of genetic diversity: ecological, demographic and lifehistory correlates, In Evolutionary Dynamics of Genetic Diversity (Lecture Notes in Biomathematics, Vol. 53), edited by Mani G.S., pp. 13-295. Springer-Verlag, Berlin. G.

Ouk M., Basnayake J., Tsubo M., Fukai S., Fischer K.S., Kang S., Men S., Thun, V. and Cooper M. (2006). Genotype-byenvironment interactions for grain yield associated with water availability at flowering in rainfed lowland rice. Field Crop. Res. 101:145-154.

Panse V.G. (1957). Genetics of quantitative characters in relation to plant breeding. Indian J. Genet. Pl. Br. 28:225-229.

Roy N. and Murty B.R (1970). A selection procedure in wheat for stress environment. Euphytica 19:509- 521.

Samarah H. (2004). Effects of drought stress on growth and yield of barley. Agron. Sustain.
Dev. 25:145-149.

Sardana S., Mahjan R., Gautam N. and Ram B. (2007). Genetic variability in pea (Pisum sativum L.) germplasm for utilization. SABRAO J. Breed. Genet, 39:31-41.

Shakhatreh Y., Kafawin O., Ceccarelli S. and Saoub H. (2001). Selection of barley lines for drought tolerance in low-rainfall. J. Agron. Crop Sci. 186:119-127.

Sinha B.C. and Saha B.C. (1999). Genetic studies, heritability and genetic advance in Barley (Hordeum vulgare L). J. Appl. Biol. 9:108116.

Steel, R.G.D and Torrie J.H. (1980). Principles and procedures of statistics. A biometrical approach. $2^{\text {nd }}$ Ed., McGraw Hill Inter. Book Co. Tokyo, Japan.

Tesemma, T., Becker H.C., Belay G., Mitiku D., Bechere E. and Tsegaye S. (1993). Performance of Ethiopian tetraploid wheat landraces at their collection sites. Euphytica, 71: 221-30.

Tesfaye T., Getachew B. and Worende M. (1991). Morphological diversity in tetraploid wheat landrace populations from the central highlands of Ethiopia. Hereditas 114:171176.

van Lammerts Bueren E.T., Struik P.C., TiemensHulscher M. and Jacobsen E. (2003). Concepts of intrinsic value and integrity of plants in organic plant breeding and propagation. Crop Sci. 43:1922-1929.

Utz H.F. (2000). PLABSTAT: A computer program for the statistical analysis of plant breeding experiments. Version $2 \mathrm{~N}$. Institute of Plant Breeding, Seed Science, and Population Genetics, University of Hohenheim, Stuttgart, Germany.

Virk D.S. and Mangat B.K. (1991). Detection of crossover genotype $\times$ environment interactions in pearl millet. Euphytica 52:193-199.

Weltzien E. (1988). Evaluation of barley (Hordeum vulgare L.) landrace populations originating from different growing regions in the Near East. Plant Breeding 101:95106.

Weltzien E. and Fischbeck G. (1990). Performance and variability of local barley landraces in near-eastern environments. Plant Breeding 104:58-67.

Woodend J.J. and Glass A.D.M. (1993). Genotype environment interaction and correlation between vegetative and grain production measures of potassium use-efficiency in 


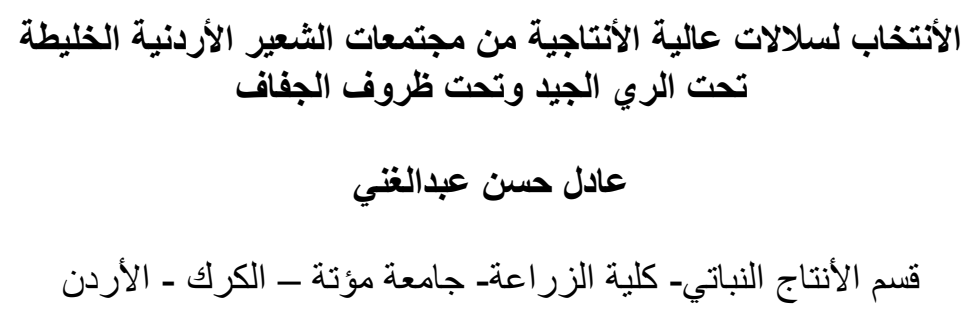

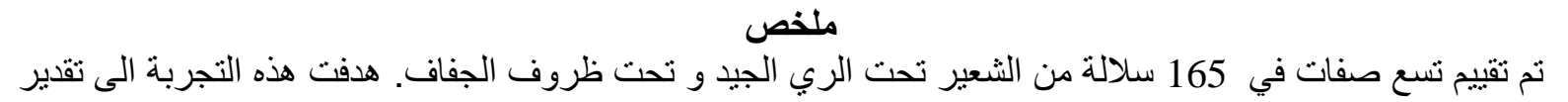

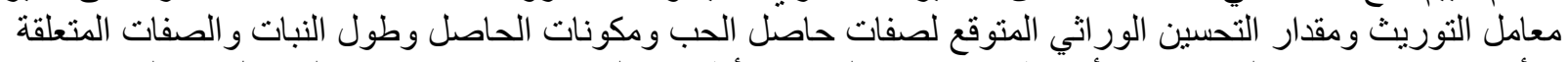

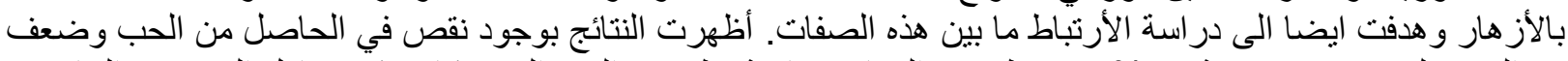

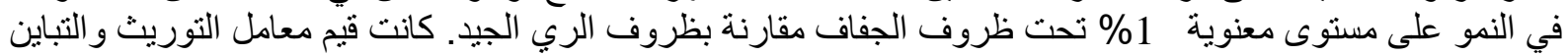

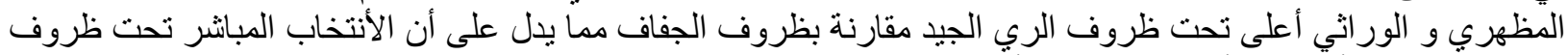

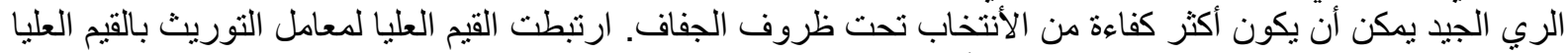

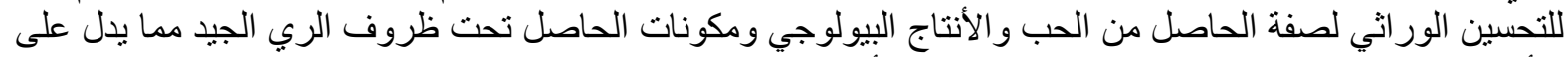

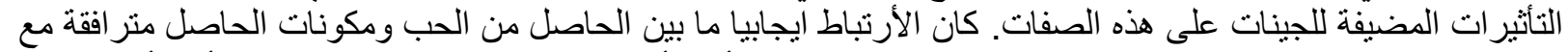

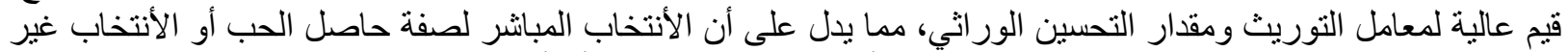

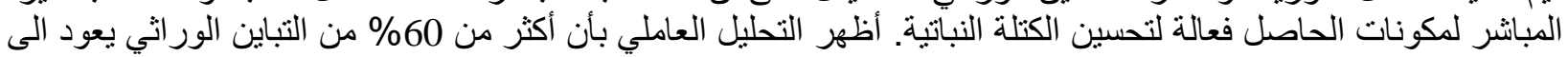

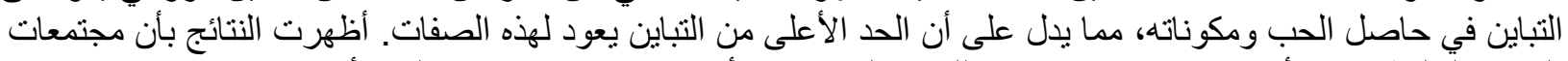

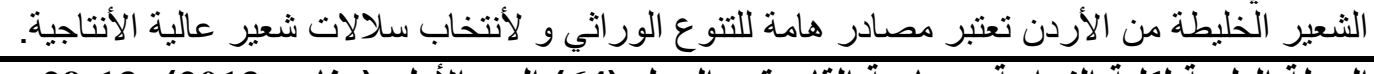

